\title{
Evaluation of the variations and potential clinical use of second trimester serum markers for the detection of pre-eclampsia
}

\author{
Savita S. Gautam*, Manmeet Kaur, Naimaa K. Chaudhary, Asha Sharma
}

Department of Obstetrics and Gynecology, St. Stephens Hospital, Delhi, India

Received: 08 May 2018

Accepted: 30 May 2018

\section{*Correspondence:}

Dr. Savita S. Gautam,

E-mail: drsavita_gwl@yahoo.co.in

Copyright: () the author(s), publisher and licensee Medip Academy. This is an open-access article distributed under the terms of the Creative Commons Attribution Non-Commercial License, which permits unrestricted non-commercial use, distribution, and reproduction in any medium, provided the original work is properly cited.

\begin{abstract}
Background: In many areas of world, hypertensive disease in pregnancy is the single most common cause of maternal death. Pregnancy associated hypertension remains unsolved despite decades of intensive research and remains the most significant problem in obstetrics. The aim of present study is to evaluate the variations and potential clinical use of second trimester serum markers for the detection of pre-eclampsia.

Methods: In an observational study, estimations of serum of human chorionic gonadotropin $(\beta-h C G)$ were done in 347 randomly selected women at 13-20 weeks of gestation in august 2015 to may 2016. Multiple of median (MOM) was calculated from charts of norms available for that weeks of pregnancy. The subjects were followed up till delivery for the development of hypertension in pregnancy and results analysed statistically with Chi-square test.

Results: Out of 347, 47 women developed hypertyension and 2MOM of $\beta$ hCG was significantly $(\mathrm{P}<0.001)$ elevated in those who developed hypertension compared to normotensive women. In our study group a significant associations between elevations in second trimester $\beta$-hCG and development of hypertension was observed. Thus with second trimester serum marker study, prediction of pre- eclampsia is possible at incipient stage and adverse pregnancy outcome can be minimized.
\end{abstract}

Conclusions: Maternal serum $\beta$-hCG level was found to be significantly higher in hypertensive group than normal group.

Keywords: $\beta$-hCG, Observational study, Pregnancy, Preeclampsia

\section{INTRODUCTION}

Hypertension in pregnancy is a unique disease seen only in pregnancy affecting $12-15 \%$ of all pregnant women. In spite of improvement in maternal and neonatal care, preeclampsia and its sequelae are a dreaded complication of pregnancy. It is indeed a constant endeavour of obstetricians to identify the risk involved in pregnancy and if possible its prediction. If prediction becomes possible, prevention will follow naturally. Several tests have been proposed but none has been accepted widely due to their low predictive value. Pre-eclampsia is a pregnancy specific disorder characterized by newly onset of blood pressure more than $140 / 90 \mathrm{mmHg}$, in at least two consecutive occasion and proteinuria (> $300 \mathrm{mg}$ per 24 hours collection) after 20 weeks of pregnancy gestational hypertension is a major pregnancy complication associated with significant fetal risks and maternal morbidity and mortality. ${ }^{1-3}$ It is responsible $25 \%$ of all fetal growth retardation and $15 \%$ preterm birth in developed countries. The incidence of pre-eclampsia in India is about $8-10 \%$ and maternal mortality due to be reported $8 \% .^{4}$ Placentas is the known primary trigger of gestational hypertension. Recent placental transcriptome theory supports the view. ${ }^{5}$ The abnormal placentation has been considered as one of the initial event in the disease 
process. Hsu et al, hypothesized that during mid trimester, immunological changes occur in the trophoblasts, resulting in secretory response, which is seen as a rise in the beta hCG levels. ${ }^{6}$

The human chorionic gonadotropin (hCG) is a glycoprotein composed of two non covalently linked subunits, $\alpha$ and $\beta$, and is produced by syncytiotrophoblast cells of the placenta. Maternal serum hCG peaks at $8-10$ week of gestation and then declines to reach a plateau at 18 - 20 wk of gestation. The free $\beta$-subunit can derive from three sources, namely, direct trophoblast cell production, dissociation of hCG into free $\alpha$ - and free $\beta$ subunits, and by macrophage or neutrophil enzymes nicking the hCG molecule. ${ }^{7}$ The free $\beta$-hCG circulating in maternal serum corresponds to only about $0.3-4 \%$ of the total hCG. ${ }^{8,9}$

In pre-eclampsia histological examination reveal focal cellular necrosis in the syncytiotrophoblast and increased mitotic activity with cellular proliferation in the cytotrophoblast. ${ }^{10}$ In addition the proliferating trophoblast in severe preeclampsia is rapidly transformed into syncytiotrophoblast within 72 hours. The normal placenta differentiates during pregnancy with the cytotrophoblast dominant in early gestation and the syncytotrophoblast dominant in late pregnancy. Placental vascular damage leading to decreased oxygen supply might result in increased hCG production by hyperplasic cytotrophoblastic cells. $^{11}$

There is a strict relationship between PIH and elevated serum $\beta$-HCG levels, indicating that there should be an abnormal placental secretary function in patients with severe pre eclampsia. Understanding the disease process and the impact of hypertensive disorders on pregnancy is of the utmost importance, because these disorders remain a major cause of maternal and perinatal morbidity and mortality worldwide. There has been an exponential increase in basic science literature exploring etiology of pre-eclampsia, yet it remains a disease of theories. Many etiological (genetic, nutritional, immunological and infectious) and pathophysiological (abnormal placentation, oxidative stress and endothelialdysfunction) pathways have been proposed as causal hypotheses for pre-eclampsia. ${ }^{1,4}$

Hypertension in pregnancy is one the most common ailments encountered during pregnancy, complicating 10$15 \%$ of pregnancies

WHO reviews hypertensive disorders of pregnancy causes $16 \%$ of maternal mortality (greater than hemorrhage $13 \%$, abortion $8 \%$, sepsis $2 \%$ ).

Complications of pre-eclampsia include eclamptic seizures, intracerebral hemorrhage, liver cell damage, DIC, pulmonary edema and acute renal failure. But importantly, it is reported now that half of this hypertension related deaths are preventable. At present there is no reliable screening test for hypertensive disorder of pregnancy during second trimester.

In our Indian set up where the follow up is poor, an initial screening test like serum $\beta$ HCG levels may help in categorising patients that require more attention.

\section{METHODS}

This present study was conducted in Department of Obstetrics and Gynaecology St Stephens hospital delhi. This present observational prospective study was done on 347 pregnant, normotensive, non-proteinuric women selected randomly between the gestational age of 13-20 weeks and the cases were followed till delivery for the development of hypertension. A structured interviewer administered questionnaire was filled for all the patients to obtain information on age, educational status, parity, occupation, ethnic group, gestational age, body mass index (BMI) and cell phone number. All pregnant women age above 18 years and below 35 years, primi gravida and multigravida were included. Women with multiple pregnancy, congenital malformation, extreme hypertension, diabetes mellitus and history of Down syndrome were excluded from the study. Gestational age was calculated from the reliable menstrual history dates and early ultrasonographical measurement of fetal crownrump length. Urinalysis for protein and glucose was done at subsequent visits when blood pressure was found to be elevated, i.e., 140/90 mmHg.Blood pressure was done by Richter's mercury sphygmomanometer, the gold standard for measuring blood pressure with a properly sized cuff and the patient in a seated position. Hypertension disorder of pregnancy was identified in case of systolic blood pressure $\geq 140 \mathrm{~mm} \mathrm{Hg}$ or diastolic blood pressure $\geq 90 \mathrm{~mm} \mathrm{Hg}$ on two occasions at least four hours apart. The Korotkov phase IV which is the fading of the blood flow murmur is recognized as the diastolic blood pressure. The beta- HCG estimation in maternal serum was done by chemiluminescent immunometric assay (CLIA) method. Multiple of median (MOM) was calculated from the median of the diagnostic test employed for the current study (Diagnostic Products Corporation, U.S, Immulite 2000- HCG), having the central $95 \%$ values accuracy.

Results were evaluated and analyzed statistically. Statistical testing was conducted with the statistical package for the social science system version SPSS 17.0. Continuous variables were presented as mean $\pm \mathrm{SD}$ or median (IQR) for non-normally distributed data. Categorical variables were expressed as frequencies and percentages. The comparisons of normally distributed continuous variables between the groups were performed using Student's t test. Nominal categorical data between the groups were compared using Chi-squared test or Fisher's exact test as appropriate. Non-normal distribution continuous variables were compared using Mann Whitney $U$ test. A receiver operating characteristics (ROC) analyses were calculated to 
determine optimal cut-off value for beta HCG. The area under the curve, the sensitivity, and the specificity were also being calculated to analyze the diagnostic value of beta HCG levels. Odds ratio and $95 \%$ CI was also be done. For all statistical tests, a p value less than 0.05 was taken to indicate a significant difference.

\section{RESULTS}

347 women were enrolled and completely followed till term. Whether they developed preeclampsia or not. Out of 347 women, 47 women developed PIH. Out of $47 \mathrm{PIH}$ patients 33 patients developed non severe PIH and 14 patients developed severe PIH. Incidence of PIH in our hospital was found $13.5 \%$. Incidence of non-severe $\mathrm{PIH}$ was $9.5 \%$ and of severe PIH was $4 \%$. (Table 1 and 2)

Table 1: Incidence of pre-eclampsia.

\begin{tabular}{|lll|}
\hline Groups & Frequency & $\%$ \\
\hline Normal & 300 & $86.5 \%$ \\
\hline PIH & 47 & $13.5 \%$ \\
\hline
\end{tabular}

Table 2: Incidence of severe and non-severe preeclampsia.

\begin{tabular}{|lll|}
\hline Groups & Frequency & $\%$ \\
\hline Severe pre-eclampsia & 14 & $30 \%$ \\
\hline Non-severe pre-eclampsia & 33 & $70 \%$ \\
\hline
\end{tabular}

In present study majority of antenatal women were in 2630 years $(47.7 \%)$ of age group. Majority of patients developing non severe preeclampsia were in 26-30 years age group and majority of patients developing severe preeclampsia were in 20-25 years age group.

No statistically significant difference was seen in age distribution of severe, non-severe preeclampsia and normal patients. But $47.7 \%$ patients developed nonsevere pre-eclampsiain 26-30 years age group and $35.7 \%$ patients developed severe preeclampsia in 20-25 years age group.

The mean value of maternal serum level of $\beta$-hCG in preeclamptic group was significantly higher than the normal group $(\mathrm{p}=<0.001)$ (Table 3$)$.

Table 3: Maternal serum level of $\beta$-hCG in normal and pre-eclamptic group.

\begin{tabular}{|c|c|c|c|c|c|c|}
\hline & \multicolumn{4}{|c|}{ PIH } & \multicolumn{2}{|l|}{ P value } \\
\hline & Normal & $\begin{array}{l}\text { Total } \\
\text { preeclampsia }\end{array}$ & Non severe & Severe & $\begin{array}{l}\text { Normal } \\
\text { Vs PIH }\end{array}$ & $\begin{array}{l}\text { Normal, severe and } \\
\text { Non severe PIH }\end{array}$ \\
\hline & Mean \pm SD & Mean \pm SD & Mean \pm SD & Mean \pm SD & \multirow{2}{*}{$<0.001$} & \multirow{2}{*}{$<0.001$} \\
\hline $\mathrm{HCG}$ & $25992 \pm 14985$ & $38498 \pm 18749$ & $38914 \pm 17182$ & $37517 \pm 22710$ & & \\
\hline
\end{tabular}

Table 4: Multiple of median value of maternal beta HCG.

\begin{tabular}{|c|c|c|c|c|c|c|}
\hline \multirow[b]{2}{*}{ MOM } & \multicolumn{3}{|c|}{ Preeclampsia } & & \multicolumn{2}{|l|}{ P value } \\
\hline & $\begin{array}{l}\text { Normal } \\
\text { Frequency } \\
(\%)\end{array}$ & $\begin{array}{l}\text { Total } \\
\text { Frequency } \\
(\%)\end{array}$ & $\begin{array}{l}\text { Non severe } \\
\text { Frequency } \\
(\%)\end{array}$ & $\begin{array}{l}\text { Severe } \\
\text { Frequency } \\
(\%)\end{array}$ & $\begin{array}{l}\text { Normal } \\
\text { Vs } \\
\text { Preeclampsia }\end{array}$ & $\begin{array}{l}\text { Normal, severe } \\
\text { and non severe } \\
\text { preeclampsia }\end{array}$ \\
\hline$<=2$ & $282(94 \%)$ & $27(57.4 \%)$ & $20(60.6 \%)$ & $7(50 \%)$ & & \\
\hline$>2$ & $18(6 \%)$ & $20(42.6 \%)$ & $13(39.4 \%)$ & $7(50 \%)$ & $<0.001$ & $<0.001$ \\
\hline Total & $300(100 \%)$ & $47(100 \%)$ & $33(100 \%)$ & $14(100 \%)$ & & \\
\hline
\end{tabular}

Chi square test $\mathrm{P}$ value-<.001

Table 5: Distribution of patients according to $<=2$ MOM and $>2$ MOM.

\begin{tabular}{|lllll|}
\hline MOM & Normal & \multicolumn{3}{c|}{ Preeclampsia } \\
\hline$<=2$ & Frequency & \% & Frequency & \% \\
\hline$>2$ & 282 & $94.0 \%$ & 27 & $57.4 \%$ \\
\hline & 18 & $6.0 \%$ & 20 & $42.6 \%$ \\
\hline
\end{tabular}

Table 6: Maternal serum level of $\geq 2$ mom of $\boldsymbol{\beta}$-hCG as a predictor test for pre-eclampsia.

\begin{tabular}{|c|c|c|c|c|}
\hline Sensitivity & Specificity & PPV & NPV & Accuracy \\
\hline $42.6 \%$ & $94.0 \%$ & $52.6 \%$ & $91.3 \%$ & $87.0 \%$ \\
\hline
\end{tabular}


Among PIH of 47 patients $\geq 2$ MOM value of beta hcg was found in 27 patients that was found statistically significant. 18 patients with $\geq 2 \mathrm{MOM}$ value of beta hcg were found normotensive (Table 4).

In our study sensitivity and specificity of $\geq 2 \mathrm{MOM}$ value of beta hcg as second trimester preeclampsia predictor was found $42.6 \%$, and $94 \%$, accuracy of test is found $87 \%$ (Table 6).

In our study 20 cases out of $47(42.6 \%)$ with values of beta $\mathrm{HCG} \geq 2 \mathrm{MOM}$ developed PIH 18 cases out of 300 (6\%), having a beta $\mathrm{HCG}$ value $\geq 2 \mathrm{MOM}$. The difference was found statistically significant.

\section{DISCUSSION}

Since the year 1950, HCG is reported to be elevated in toxemic pregnancy. In preeclampsia the rise of blood pressure is due to vasoconstriction and impaired angiogenesis leading to hypoxia and hyperplasia of trophoblastic cells which causes hyper secretion of placental hormone ultimately leading tohigh level of circulation $\beta$-hCG. In pre-eclampsia, the cytotrophoblast transformed into syncytiotrophoblast. Human placenta synthesizes steroid, protein, and glycoprotein hormones throughout gestation. ${ }^{12}$ The production of hCG by the placenta in early pregnancy is critical for implantation and maintenance of the blastocyst. Since it is postulated that preeclampsia is likely a trophoblastic disorder. RemziGokdeniz et al, found a strict relationship between severe pre - eclampsia and elevated serum $\beta$ - hCG levels, indicating that should be an abnormal placental secretary function in patients with severe pre - eclampsia. ${ }^{13}$ In 1934, Smith et al talked about increasing hCG levels in severe preeclampsia for the first time. ${ }^{14}$

In our study women with higher levels of beta HCG $(\geq 2$ MOM) during the second trimester of pregnancy, developed $\mathrm{PIH}$ later in their pregnancy, with $\mathrm{P}$ value $<0.001$ which was statistically highly significant. $42.6 \%$ of women with elevated levels of beta HCG developed PIH with sensitivity $42.6 \%$, specificity $94 \%$ and the positive predictive value $52.6 \%$.

In a study by Kaur $\mathrm{G}$. et al, they found sensitivity was $90.91 \%$, specificity was $97.44 \%$ and positive predictive value was $83.33 \%$ for beta $\mathrm{HCG}$ as mid trimester predictor test. $^{15}$

In a study conducted by Chaudhari et al, they observed that the higher absolute levels of beta HCG strongly correlate with occurrence of gestational hypertension. Out of 190 Pregnant women, 25 women who developed gestational hypertension were having higher absolute levels of beta HCG as compared to 165 pregnant women who did not $($ Mean \pm SD; $54907 \pm 29509$ vs $41095 \pm 19103$; $\mathrm{p}<0.001) .{ }^{16}$
In a study conducted by Ashour et al on 6286 nondiabetic women with singleton pregnancies, the sensitivity of beta-human chorionic gonadotropin as a screen for development of hypertension was $15.6 \%$, the specificity was $90.0 \%$, and the positive predictive value was $12.8 \% .^{17}$

Sharma V et al in their study observed that out of 387 cases with beta-HCG levels 2MOM, 49 cases $(81.67 \%)$ developed pregnancy induced hypertension $(\mathrm{p}<0.001) .{ }^{18}$

In our study, 20 cases out of $47(42.6 \%)$ with values of beta $\mathrm{HCG} \geq 2 \mathrm{MOM}$ developed PIH 18 cases out of 300 (6\%), having a beta $\mathrm{HCG}$ value $\geq 2 \mathrm{MOM}$. The difference was found statistically significant.

\section{CONCLUSION}

The study concluded that measuring second trimester serum Beta- HCG levels is a good predictor of pregnancy induced hypertension and helps in risk stratification of women destined to develop pregnancy induced hypertension in the same pregnancy. Thus these women can be followed up in a tertiary care centre for further management of beta HCG which is associated with severity of PIH.

\section{Funding: No funding sources}

Conflict of interest: None declared

Ethical approval: The study was approved by the Institutional Ethics Committee

\section{REFERENCES}

1. Sharma P, Maheshwari S, Barala S. Correlation between second trimester beta human chorionic gonadotropin levels and pregnancy outcome in high risk group. Int J Reprod Contracept Obstet Gynecol. 2016;5(7):2358-61.

2. Anand S, Kirshnanand. Perinatal outcome in growth retarded babies born to normotensive and hypertensive mothers: a prospective study. BMC Cardiovasc Disord. 2015;15:111.

3. Ananth CV, Basso O. Impact of pregnancy-induced hypertension on stillbirth and neonatal mortality in first and higher order births: a population-based study. Epidemiology. 2010;21(1):118-23.

4. Powers RW, GallaherMJ, Frank MP, Daftary AR, et al. Uric acid concentrationsin early pregnancy among preeclamptic womenwith gestational hyperuricemia at delivery. Am J Obstet Gynecol. 2006;194(1):160.

5. Jain K, Kavi V, Raghuveer CV, Sinha R. Placental pathology in pregnancy induced hypertension (PIH) with or without intrauterine growth retardation. Indian J Pathol Microbiol. 2007;50(3):533-7.

6. Sober S, Reiman M, Kika T, Rull K, Inno R, Vaas P, et al. Extensive shift in placental transcriptome profile in preeclampsia and placental origin of adverse pregnancy outcomes. Sci Rep. 2015;5:133-6. 
7. Hsu CD, Chan DW, Iriye B. Elevated serum human chorionic gonadotropin as evidence of secretory response in severe pre eclampsia. Am J Obstet Gynaecol. 1994;170;1135-8.

8. Cole LA, Kardana A, Park SY, Braunstein GD. The deactivation of hCG by nicking and dissociation. J Clin Endocrinol Metab. 1993;76(3):704-10.

9. Spencer K. Evaluation of an assay of the free betasubunitof choriogonadotropin and its potential value in screeningfor Down's syndrome. Clin Chem. 1991;37(6):809-14.

10. Fuhrmann W, Altland K, Jovanovic V. Firsttrimester alpha fetoprotein screening for Down syndrome. Prenat Diagn. 1993;13(3):215-8.

11. Jones CJ, Fox H. An ultra-structural and ultrahistochemical study of the human placenta in maternal pre-eclampsia. Placenta. 1980;1(1):61-76.

12. Majumdar S, Dasgupta $\mathrm{H}$, Bhattacharya $\mathrm{K}$, Bhattacharya A. A study of placenta in normal and hypertensive pregnancies. J Ant Soc India. 2005;54(2):1-9.

13. Shima DT, Maihos C. Vascular developmental biology: getting nervous. Curr Opin Genet Dev. 2000;10(5):536-42.

14. Remzi G, Erdal A, Nursel B, Ozcan B. Elevated serum - hCG levels in severe Preeclampsia. Turk $\mathbf{J}$ Med Sci. 2000;43-5.

15. Smith GC, Smith OW. Excessive gonado stimulatory hormone and subnormal amounts of oestin I toxaemia of late pregnancy. Am J Obstet Gynecol. 1934;107:128-45.

16. Kaur G, Jain V, Mehta S. Prediction of PIH by Maternal Serum Beta HCG Levels in the Second Trimester (13-20 Weeks) of Pregnancy. The J Obstet and Gynecol India. 2012;62(1):32-4.

17. Chaudhary H, Khursheed R, Setal P. Utility of second trimester beta HCG levels in prediction of gestational hypertension: a prospective cohort study. Int J Reprod Contracept Obstet Gynecol. 2017;6(3):1040-4.

18. Ashour AM, Lieberman ES, Haug LE, Repke JT. The value of elevated second-trimester beta-human chorionic gonadotropin in predicting development of preeclampsia. Am J Obstet Gynecol. 1997;176(2):438-42.

19. Sharma V, Sharma P, Firdous N. Beta HCG in mid trimester as a predictor of pregnancy induced hypertension. Int J Sci Res. 2016;5:303-5.

Cite this article as: Gautam SS, Kaur M, Chaudhary NK, Sharma A. Evaluation of the variations and potential clinical use of second trimester serum markers for the detection of pre-eclampsia. Int $\mathbf{J}$ Reprod Contracept Obstet Gynecol 2018;7:2904-8. 